\title{
Advanced analysis of members with gusset plate joints
}

\author{
M. Vild \\ Faculty of Civil Engineering, Brno University of Technology, Brno, Czech Republic \\ V. Chalupa \& L. Šabatka \\ IDEA StatiCa, Brno, Czech Republic \\ F. Wald \\ Faculty of Civil Engineering, Czech Technical University in Prague, Prague, Czech Republic
}

\begin{abstract}
The compressive resistance of truss members connected by gusset plates is estimated by taking the buckling length of the member equal to the member length. Usually, no check is provided for the gusset plate, although several design methods were proposed in the past. The paper presents an advanced member analysis, a design-oriented finite element method of a member including its joints. Geometrically and materially nonlinear analysis with imperfections is used to determine the load resistance of the joint-member-joint subsystem. Component-based Finite Element Method is used for joints; i.e. bolts and welds are modeled by nonlinear springs with properties based on design codes.

The advanced analysis is demonstrated on two cases. The buckling length of angles, vastly used for masts, may be assumed smaller than the theoretical length if the boundary conditions determined by bolted gusset plates provide sufficient stiffness. The experiments and detailed numerical analysis performed at the Graz University of Technology are used for validation of the advanced analysis.

The buckling resistance of gusset plates may govern the compressive resistance of the bracing. The experiments performed at the Czech Technical University in Prague (Vesecký), together with analytical design methods, are used for validation of buckling resistance of bolted eccentric gusset plate joints of circular hollow section braces.

The results depend on the chosen shape and amplitude of initial imperfections. Using recommended procedures, the proposed method provides results very close to the experiments.
\end{abstract}

\section{INTRODUCTION}

A novel design method using a model of a member together with its joints is presented. The advantage of this method is shown on two sets of examples - angles with gusset plate joints and eccentric gusset plate joints of braces. In both cases, the boundary conditions are unclear and traditional analytical models use significant simplifications. The experiments and research finite element models from literature are compared to the new method.

The design method uses component-based finite element method (CBFEM) where plates are modeled by shell finite elements and bolts and welds as special nonlinear elements based on design codes (Wald et al. 2020). The analysis model is generated automatically. The analysis has three stages: (i) materially nonlinear analysis, (ii) linear buckling analysis, (iii) geometrically and materially nonlinear analysis with imperfections. 


\subsection{Angles}

Steel angles are very commonly used in industrial structures or masts where they are typically eccentrically connected by gusset plates. The buckling length is simply assumed equal to system

length and any eccentricity is neglected. The boundary conditions are in fact difficult to determine. They depend on the thickness and length of the gusset plate, as well as the number of bolts or length of welds. Furthermore, the principal axes of angles do not coincide with axes of gusset plates. Utilizing the stiffness of joints may bring a lot of value to structures composed of steel angles.

\subsection{Eccentric joints of braces}

Flaws in design of eccentric gusset plate joints are responsible for several building collapses each year. No design guidelines are given in Eurocodes; just EN 1993-1-5 provides buckling curves for general plates. Several analytical design methods exist, e.g. Whitmore, Thornton, Modified Thornton, and Khoo, Perrera, Albermani, but none provides accurate results for all joint types. Whitmore (1952) proposed to use a dispersion angle to determine an effective section, for which steel yield resistance is calculated. Thornton (1984) modified Whitmore's method by widening the dispersion angle and to take into account buckling. Yam \& Cheng (2001) further modified the method to take into account plasticity. Khoo et al. (2009) proposed another method based on observed collapse mechanism of an experimental series. The first three methods give unconservative results for eccentric gusset plate joints by hundreds of percents. Only the method by Khoo et al. is close to reality (Vesecký, 2019a).

Component-based finite element method allows to assess the brace including its joints. Although the method is much more sophisticated, current computational power allows very fast calculation - in seconds, which is comparable with other analytical methods. The method removes most of the simplifications of analytical methods and leaves only the unknown of initial imperfections.

The experiments performed at Czech Technical University in Prague (Vesecký et al. 2019a) were used for CBFEM validation.

\section{METHODS}

\section{$2.1 \quad C B F E M$}

CBFEM for steel members allows to analyze buckling of a substructure system - member including its joints. The analyzed member as well as its joints are composed of shell finite elements. The components - welds and bolts - consist of multipoint constraints and nonlinear springs with properties (stiffness, resistance, deformation capacity) based on design codes, such as EN 1993-1-8. The related members starting at the joints are modeled by simple bar elements and ended by a support or loaded by a force or moment. The forces can be also directly applied to the plates of analyzed member. For an example of a CBFEM model; see Figure 1. IDEA StatiCa Member (IDEA StatiCa, 2020) application was used in this study.

Three types of analysis may be performed:

1. Materially nonlinear analysis (MNA),

2. Linear buckling analysis (LBA),

3. Geometrically and materially nonlinear analysis with imperfections (GMNIA).

GMNIA is the most sophisticated numerical analysis for static loading. Validated models are deemed trustworthy and are often used even for formulation of analytical formulas in codes. 


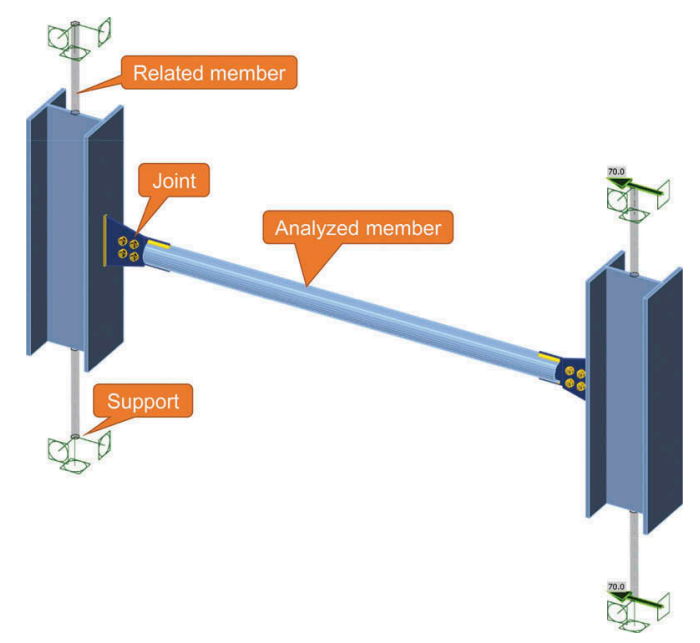

Figure 1. Model of specimen $\mathrm{C} 1$ - eccentric joint of a brace.

\subsection{Angles}

Experiments by Kettler et al. (2019) are used for validation of the model, and the recommendations given in Kettler et al. (2017) are used for modeling. A total of 9 selected cases are analyzed. The designation of individual specimens is maintained (A1-A3), (A4-A6), and (E1E3). Bolts M20 10.9 were used for specimens A1-A6 and bolts M27 10.9 for specimens E1E3. All bolts were preloaded. Their real cross-section dimensions are considered, as well as their real material properties. Two different sets of boundary conditions are investigated ( $\mathrm{BC} 1$ - rigid, $\mathrm{BC} 2$ - uniaxially hinged; see Figure 2); there is also a variance in the column's relative slenderness.

The inputs of the calculation are summarized in Table 1 . The cross-section dimensions and material properties are presented, as well as the value of initial imperfection $e_{0}$ assumed as $L /$ 300 (Kettler et al. 2017) in the shape of the first buckling mode shape, which is decisive for the angle.

\subsection{Eccentric joints of braces}

The series comprises six specimens; three are connected perpendicularly (labeled C) and three at $45^{\circ}$ (labeled D). The connecting plate is welded into CHS of the brace, and two or four bolts are used to fasten the connecting plate to the gusset plate. The model of specimen $\mathrm{C} 1$ is shown in Figure 1.

a)

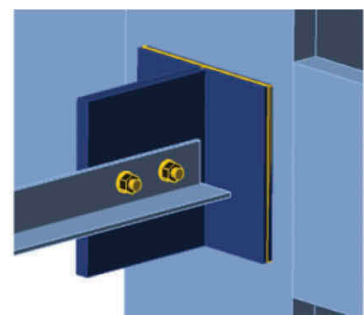

b)

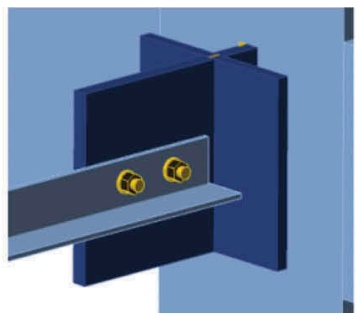

c)

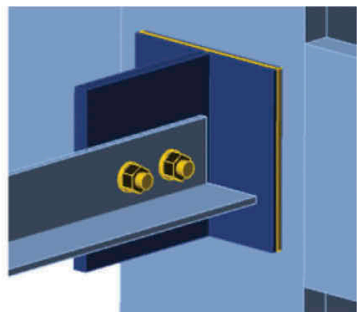

Figure 2. Boundary conditions of steel angles: a) A1-A3: rigid, b) A4-A6: uniaxially hinged, c) E1-E3: rigid. 
Table 1. Geometry, material properties, and used amplitude of equivalent imperfection.

\begin{tabular}{lllllll}
\hline Index & $L[\mathrm{~mm}]$ & Cross-section & Supports & $E[\mathrm{GPa}]$ & $f_{\mathrm{y}}[\mathrm{MPa}]$ & $e_{0}[\mathrm{~mm}]$ \\
\hline A1 & 1140 & L $80.4 \times 8.2$ & BC1 & 212 & 289.9 & 3.8 \\
A2 & 1820 & L $80.3 \times 8.1$ & BC1 & 212 & 289.9 & 6.1 \\
A3 & 2630 & L $80.4 \times 8.3$ & BC1 & 212 & 289.9 & 8.8 \\
A4 & 870 & L $80.3 \times 8.2$ & BC2 & 212 & 289.9 & 2.9 \\
A5 & 1550 & L $80.3 \times 8.2$ & BC2 & 212 & 289.9 & 5.2 \\
A6 & 2360 & L $80.3 \times 8.2$ & BC2 & 212 & 289.9 & 7.9 \\
E1 & 1850 & L $120.3 \times 12.0$ & BC1 & 192 & 299.3 & 6.2 \\
E2 & 3170 & L $120.1 \times 12.0$ & BC1 & 192 & 299.3 & 10.6 \\
E3 & 4200 & L $120.3 \times 12.0$ & BC1 & 192 & 299.3 & 14.0 \\
\hline
\end{tabular}

The imperfections have a significant impact on the results of GMNIA. The guidelines for imperfections specifically for gusset plates are not codified. The aim of this paper is not to select the most suitable amplitude and buckling mode shape for the buckling analysis of gusset plate joints. Unterweger \& Taras (2013) suggest that that the second buckling mode shape may be more dangerous for the gusset plate. Therefore, the first and second buckling mode shapes are investigated. The amplitude of initial imperfection is chosen as (1) $L / 200$, where $L$ is the system length of the CHS brace, and (2) $L_{\text {gusset }} / 50+L_{\text {member }} / 1250$, where $L_{\text {gusset }}$ is the length of the gusset plate and $L_{\text {member }}$ is the length of the CHS brace.

\section{RESULTS AND DISCUSSION}

\subsection{Angles}

Kettler et al. (2019) complemented the experimental study with the research-oriented finite element models (ROFEM). Their results were added to the comparison of CBFEM model and experiments. The comparison of LBA results of numerical models and GMNIA results to experiment is in Figure 3. The results of LBA verification are satisfactory, critical loads from both software solutions are very similar in all but one case (A4), where the difference in results
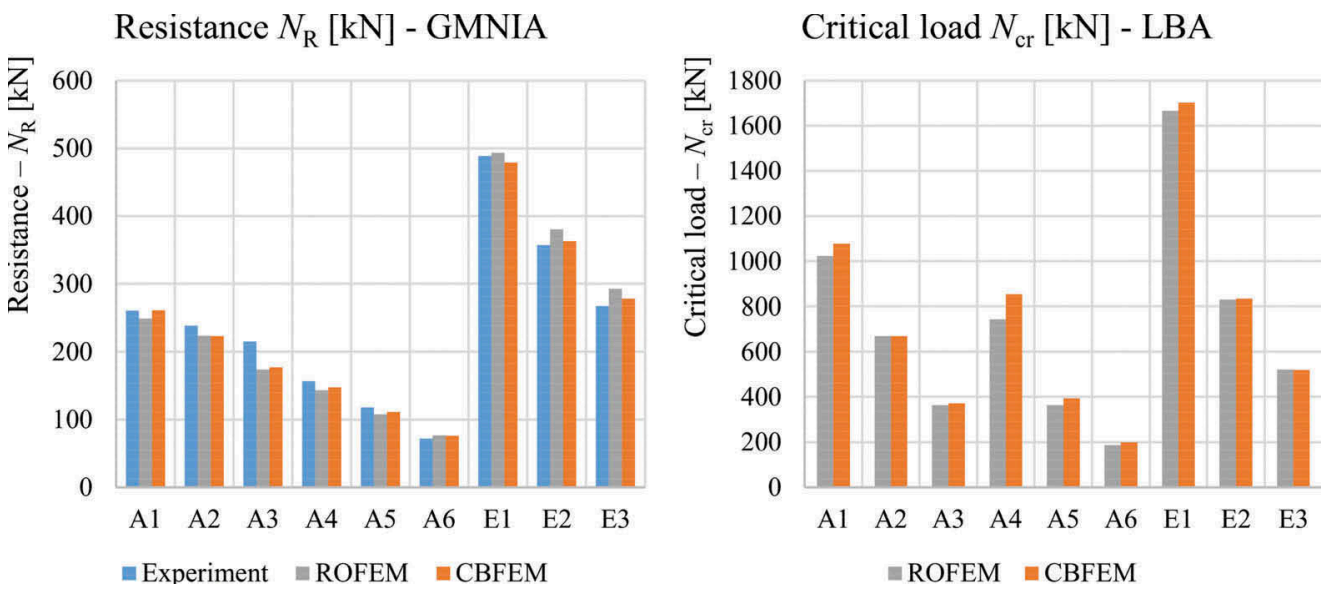

Figure 3. Comparison of CBFEM to experiments and research-oriented finite element models (Kettler et al. 2019). 
is $13 \%$. In all the other cases, the difference is under 5\%. The results of GMNIA validation show a good agreement with the experimental data. In fact, the CBFEM results are slightly closer to the experimental ones than the research-oriented finite element model created specifically for this experiment. There is also a good agreement when verifying the results of CBFEM to ROFEM, with the largest deviation under 5\%.

\subsection{Eccentric joints of braces}

The CBFEM results of author's models are compared to experimental results, analytical methods and research-oriented finite element models using imperfections measured by digital image correlation (ROFEM - DIC) and by EN 1993-1-5 (ROFEM - EN) (Vesecký, 2019b). It can be seen that analytical methods by Whitmore, Thornton, and Yam \& Cheng extremely overestimate the resistance of eccentric gusset plate joints. Method by Khoo et al. is closer to experimental resistances, but it underestimates the resistance of diagonal braces, predicting in average only half of their experimental resistances; see Figure 4.

In CBFEM, the first two buckling mode shapes from LBA were investigated; see Figure 5. Both critical buckling load factors are very close to each other.

In Figure 6, the effect of imperfections on the resulting load resistance determined by GMNIA in CBFEM is shown. The imperfections using the first buckling mode (1st - L/ 200) provide significantly higher resistance than the imperfections using the second buckling mode (2nd - L/200), confirming the theory of Unterweger \& Taras (2013). The second buckling mode is critical for the eccentric gusset plate joint. In both cases,

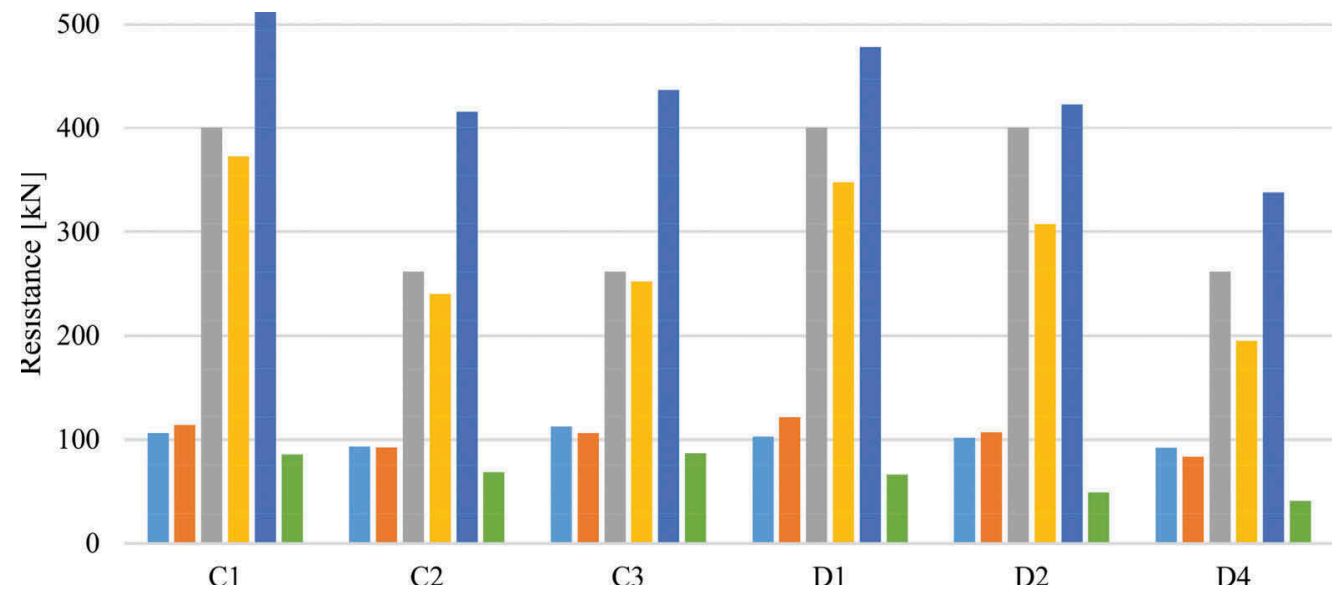

Figure 4. Comparison of CBFEM to experiments and analytical methods (Vesecký, 2019a).
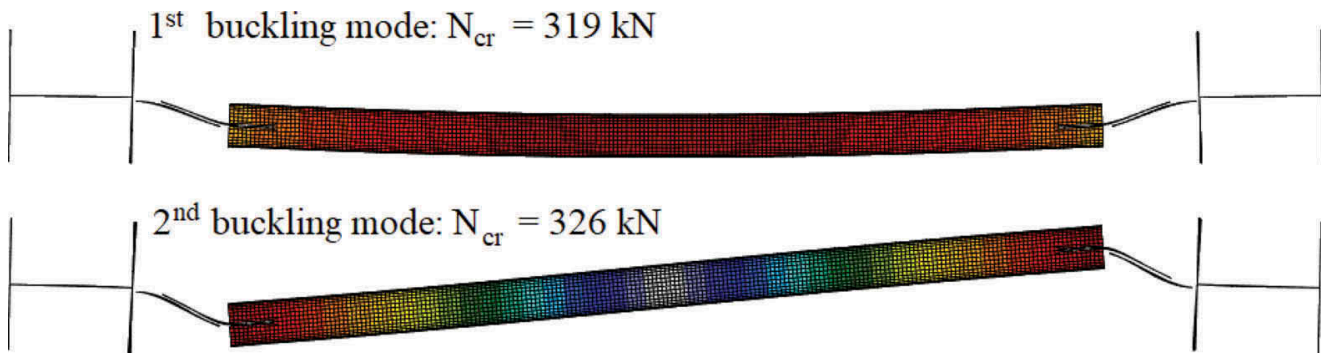

Figure 5. First two buckling mode shapes of braces with eccentric gusset plate joints. 
a)

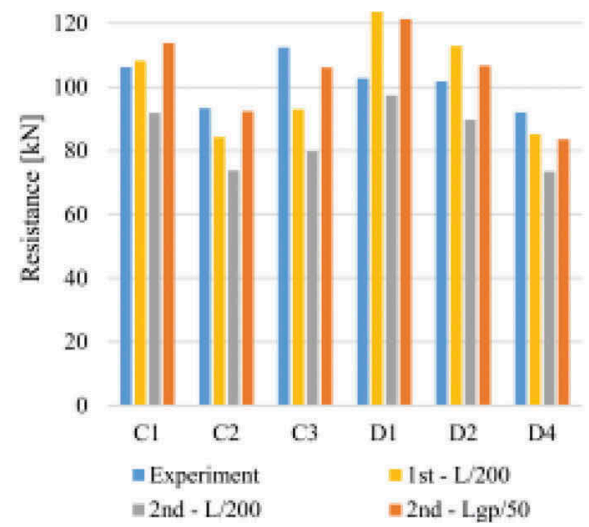

b)

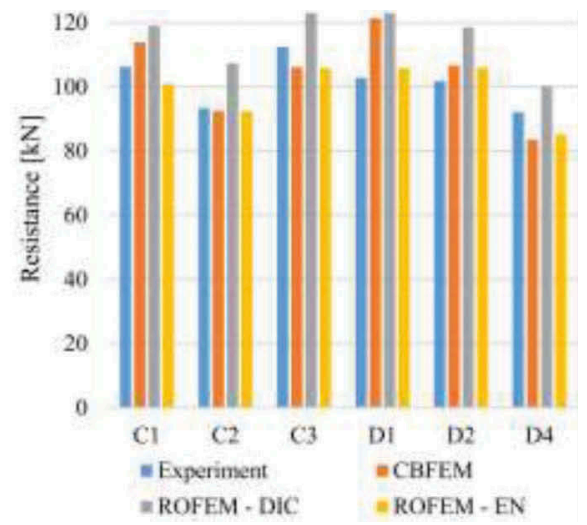

Figure 6. CBFEM GMNIA with different imperfections a) and comparison to experiments and ROFEMs b).

the amplitude of initial imperfections is taken as $L / 200$ where $L$ is the system length of the angle. The chosen amplitude of imperfections is too high for this set of experiments; the resistances are in all cases lower (in average at 83\%). Therefore, also the amplitudes of imperfection suggested by Vesecký are used with the second buckling mode shape: $L_{\text {gusset }} / 50+L_{\text {member }} / 1250$ where $L_{\text {gusset }}$ is the length of the gusset plate and $L_{\text {member }}$ is the length of the CHS brace (labeled $2 \mathrm{nd}-\mathrm{Lgp} / 50$ in Figure 6). The average is very close, at $102 \%$; however, the specimen D1 is quite unsafe at $118 \%$ of experimental resistance. It seems that the most suitable amplitude of imperfections should be higher. Nevertheless, these imperfections were chosen for further comparison with research-oriented numerical models published in Vesecký et al. (2019b).

Research-oriented numerical models with the same amplitude of initial imperfections according to EN 1993-1-5 made in ABAQUS (ROFEM - EN) provide slighly more accurate results. The research-oriented finite element models using DIC (ROFEM - DIC) should theoretically provide the most accurate prediction. However, it slightly overestimates the resistance in all cases, in average by $14 \%$. That can be explained by absence of residual stresses in the model. The equivalent imperfections should be used.

\section{CONCLUSION}

The CBFEM model in application IDEA StatiCa Member automatically creates an advanced numerical model. The model can be created and solved in minutes and allows design of members with their joints even if buckling is a governing failure mode. This is possible by geometrically and materially nonlinear analysis with imperfections.

The results show that CBFEM model can accurately predict the resistance of members with gusset plate joints. Two sets of experiments are presented; in both cases, the determination of boundary conditions as an input to codified procedures for buckling of members is questionable. The resistance of steel angles may be assumed much higher in the design process by taking real boundary conditions into account. The eccentric gusset plate joints simplify the assembly process, but are often a source of failure. The CBFEM model can reveal this failure mode and predict the load resistance of the joint much more accurately than any analytical methods.

The load resistance of models affected by buckling are susceptible to the selected buckling mode shapes and amplitudes of initial imperfections. The imperfections are codified for standard cases but care must be taken for novel cases. Higher amplitudes provide safer results but the first buckling mode shape may not include the governing failure mode. 


\section{ACKNOWLEDGMENT}

The work was prepared under the $\mathrm{R} \& \mathrm{D}$ project supported by Technology Agency of the Czech Republic, No FW01010392.

\section{REFERENCES}

EN 1993-1-5, Eurocode 3, Design of steel structures, Part 1-5: Plated structural elements, CEN, Brussels, 2006.

EN 1993-1-8, Eurocode 3, Design of steel structures, Part 1-8: Design of joints, CEN, Brussels, 2005.

IDEA StatiCa, Member: Theoretical background. 2020. Available at: https://www.ideastatica.com/sup portcenter/idea-statica-member-theoretical-background.

Kettler, M., Lichtl, G. \& Unterweger, H. Experimental tests on bolted steel angles in compression with varying end supports. Journal of Constructional Steel Research. 155 (2019). 301-315.

Kettler, M., Taras, A. \& Unterweger, H. Member capacity of bolted steel angles in compression: Influence of realistic end supports. Journal of Constructional Steel Research. 130 (2017). 22-35.

Khoo, X. E, Perera, M. \& Albermani, F. 2009. Design of eccentrically connected cleat plates in compression. Advanced Steel Construction. 6(2): 678-687.

Thornton, W. 1984. Bracing Connections for Heavy Construction. Engineering Journal. 21: 139-148.

Unterweger, H. \& Taras, A. Compression Members with Hollow Sections and Concentric Slotted Gusset Plates - Behavior and Recommended Design Model. In Proceedings of the Annual Stability Conference, Structural Stability Research Council, St. Louis, Missouri, April 16-20, 2013.

Vesecký, J., Cábová, K. \& Jandera, M. Tests of gusset plate connection under compression. In: Wald, F. $\&$ M. Jandera, eds. Proceedings of the International Colloquia on Stability and Ductility of Steel Structures (SDSS 2019). Stability and Ductility of Steel Structures 2019, Praha, 2019-09-11/2019-09-13. Leiden: CRC Press/ Balkema,2019. 1218-1226. ISBN 9780367335038.

Vesecký, J., Cábová, K. \& Jandera, M. Numerical modelling of gusset plate connections under eccentric compression. In: Wald, F. \& M. Jandera, eds. Proceedings of the International Colloquia on Stability and Ductility of Steel Structures (SDSS 2019). Stability and Ductility of Steel Structures 2019, Praha, 2019-09-11/2019-09-13. Leiden: CRC Press/ Balkema,2019. 1218-1226. ISBN 9780367335038.

Wald, F. et al. Component-based finite element design of steel connections. Czech Technical University Prague, 2020. ISBN 978-80-01-06702-4 print, ISBN 978-80-01-06703-1 online. 245.

Whitmore, R. E. 1952. Experimental Investigation of Stresses in Gusset Plates. Knoxville: Engineering Experimental Station, University of Tennessee.

Yam, M. C H \& Cheng, J. J. R. 2001. Behavior and design of gusset plate connections in compression. Journal of constructional steel research. 58: 1143-1159. 